\title{
An optoelectric professional's training model based on Unity of Knowing and Doing theory
}

Shiqiao Qin, Wei Wu, Jiaxing Zheng, Xingshu Wang, Yingwei Zhao

Shiqiao Qin, Wei Wu, Jiaxing Zheng, Xingshu Wang, Yingwei Zhao, "An optoelectric professional's training model based on Unity of Knowing and Doing theory," Proc. SPIE 10452, 14th Conference on Education and Training in Optics and Photonics: ETOP 2017, $104520 Z$ (16 August 2017); doi: $10.1117 / 12.2268549$

Event: 14th Conference on Education and Training in Optics and Photonics, ETOP 2017, 2017, Hangzhou, China 


\title{
An Opto-electric Professionals Training Model based on "Unity of Knowing and Doing” Theory
}

\author{
Shiqiao Qin, Wei Wu, Jiaxing Zheng, Xingshu Wang, Yingwei Zhao* \\ College of Opto-electric Science and Engineering, National University of Defense Technology \\ *Email: yingweizhao@live.cn
}

\begin{abstract}
The "Unity of Knowing and Doing" (UKD) theory is proposed by an ancient Chinese philosopher, Wang Shouren, in 1508 , which explains how to unify knowledge and practice. Different from the Chinese traditional UKD theory, the international higher education usually treats knowledge and practice as independent, and puts more emphasis on knowledge. Oriented from the UKD theory, the College of Opto-electric Science and Engineering (COESE) at National University of Defense Technology (NUDT) explores a novel training model in cultivating opto-electric professionals from the aspects of classroom teaching, practice experiment, system experiment, design experiment, research experiment and innovation experiment (CPSDRI). This model aims at promoting the unity of knowledge and practice, takes how to improve the students' capability as the main concern and tries to enhance the progress from cognition to professional action competence. It contains two hierarchies: cognition (CPS) and action competence (DRI). In the cognition hierarchy, students will focus on learning and mastering the professional knowledge of optics, opto-electric technology, laser, computer, electronics and machine through classroom teaching, practice experiment and system experiment (CPS). Great attention will be paid to case teaching, which links knowledge with practice. In the action competence hierarchy, emphasis will be placed on promoting students' capability of using knowledge to solve practical problems through design experiment, research experiment and innovation experiment (DRI). In this model, knowledge is divided into different modules and capability is cultivated on different levels. It combines classroom teaching and experimental teaching in a synergetic way and unifies cognition and practice, which is a valuable reference to the opto-electric undergraduate professionals' cultivation.
\end{abstract}

Key words: The UKD theory, Training model, Opto-electric professionals, Knowledge, Experiment, Competence

\section{Introduction}

The "Unity of Knowing and Doing" (UKD) theory is an ancient Chinese philosophic thought, which explains the relationship between knowledge and action. Essentially, this theory is not only applied to knowledge and action, but also reflects a basic attitude to being of man, studying and behaving. The core of the UKD theory contains two aspects: 1. Knowing and Doing are unified and inseparable. Knowing is contained in Doing, and Doing is contained in Knowing, too. 2. Knowing is the base of Doing and directs Doing ${ }^{[1]}$. The relationship between knowledge learning and practice can be taken as an example of the UKD theory: On the one hand, practice has to be conducted during knowledge learning. Otherwise, it is impossible to master the knowledge learned. Besides this, some new knowledge can be obtained during practice, and practice can enhance the understanding of the knowledge learned. Knowledge learning and practice co-exist within one family and cannot be spilt. On the other hand, knowledge learning aims at being put into practice. The effectiveness of practice is determined by the proficiency in the knowledge learned, which requires that practice and problem-solving skills should also be included in the classroom teaching and that theory should play a directive role in the practice teaching. This can achieve the enhancement in understanding the theory ${ }^{[2]}$. Moreover, in the higher

14th Conference on Education and Training in Optics and Photonics: ETOP 2017, edited by Xu Liu,

Xi-Cheng Zhang, Proc. of SPIE Vol. 10452, 104520Z · C 2017 ICO, IEEE, OSA, SPIE

CCC code: $0277-786 X / 17 / \$ 18 \cdot$ doi: $10.1117 / 12.2268549$

Proc. of SPIE Vol. 10452 104520Z-1 
education field, knowledge should be taken as the guide of practice, while practice results from knowledge and can help acquire truth. Knowledge can be furthermore enhanced during practice. Higher education should aim at achieving that knowledge and practice are highly unified and neither of them is dispensable ${ }^{[3]}$. When the UKD theory is implemented into the modern knowledge system and educational philosophy, "Knowing" refers to mastering the laws of nature, and "Doing" refers to proceeding in accordance with the laws of nature. Only if Doing is contained in Knowing, it is possible to master the knowledge learned and seek for the truth. Doing is the final target of Knowing, while Knowing should be examined by Doing, which is of great aid for students to understand knowledge and master true skills and genuine knowledge.

\section{Opto-electric expertise teaching at NUDT}

In cultivating undergraduate students of opto-electric major at National University of Defense Technology (NUDT), the UKD theory is firstly illustrated by the cognition of opto-electric expertise. Opto-electric major is typical of multi-disciplines. According to the modern higher educational philosophy of broad caliber, the courses of opto-electric major in undergraduate study generally involve optics, laser, opto-electric technology, computer, electronics, machining, communication, signal and system and so on. As a reflection of the UKD theory, these courses are divided into several modules at NUDT, which are constituted by optical module, laser module, opto-electric module, computer module, electronic module and mechanical module as shown in Fig. 1. The optical module consists of physical optics, applied optics and the relevant optical experiments. The laser module contains laser principle, laser technique, and the relevant experiments. The opto-electric module is constituted by the knowledge and experiments related to lighting, spectrum, detection, display and so on. The computer module involves computer hardware and software courses and experiments including computer principles, programming and so on. The electronic module is comprised by analogue electronic technology, digital electronic technology and the relevant experiments. The mechanical module includes mechanical drawing and metalworking practice.

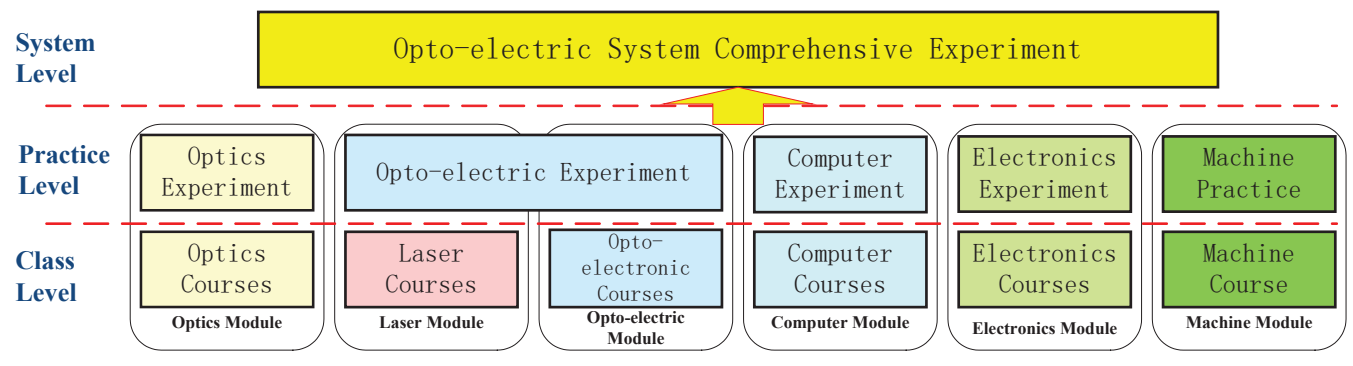

Fig. 1 Structure diagram of knowledge modules in opto-electric major

Each knowledge module contains two levels: Classroom teaching and practice teaching. Classroom teaching mainly concerns learning and exercising professional theoretical knowledge. It focuses on explaining basic concepts, theoretical derivation, conclusion, system structure, application field, defects and discussion. In the theoretical teaching, cognitive laws will be followed from simple to complicate. More importantly, according to the UKD educational philosophy, lots of exercises and homework will be arranged to students, which require them to use both hands and brain to finish. Some tests related to basic concepts and some discussions about how to use theory to solve practical problems will also be organized in class. A majority of after-class homework will be assigned to students to help them link theory with practice, 
which can strengthen the understanding of theory, improve the capability of theoretical design and application and achieves the purpose that Knowing is contained in Doing.

Practice teaching aims at helping students experience the knowledge learned through experiments, which are closely related with courses, and consequently promotes the understanding of the knowledge learned. In the meanwhile, it is also a good exercise for students to improve the capability of using theory to guide practice. Therefore, the experiments in this level mainly refer to cognition experiments. In order to attain the goal that Knowing is contained in Doing, optical experiments involve a series of experiments such as physical optics, spectrum experiment, geometric optics, crystal optics, high-precision optical measurement and optical system design. These experiments will cooperate with classroom teaching to strengthen the interpretation of optical knowledge and enhance the knowledge-applying ability. Opto-electric technological experiments are constituted by performance experiences of different opto-electric detectors, performance tests of different light sources such as LED, CCD array and image detector experiment, gas/solid/semi-conductor laser experiments, laser technique experiment, opto-electric high-precision measurement experiment, display experiment and so on. These experiments will further strengthen the interpretation of opto-electric knowledge, and improve the opto-electric knowledge-applying ability. Computer experiments consist of programming and interface experiments. These experiments will be assigned after class, which can foster the students' programming capability, especially the capability of using standard interfaces to interact information with outer devices. Electronic technological experiments include analog amplification, signal processing, digital logic circuit, programmable logic device (PLD) and AD/DA converters. These experiments emphasize on cultivating students' competence of circuit design and manufacturing, which are also beneficial to interpret the knowledge and theory learned. Metalworking practice focuses on letting students experience precision machining and basic metalworking operations such as lathe work, boring work and planing work.

As mentioned, opto-electric expertise possesses the characteristics of multi-discipline. Therefore, students will be trained to master not only the expertise and competence in optics and opto-electric technology, but also the multi-disciplinary knowledge and competence in electronics, computer, signal and system, communication and machining. On the one hand, due to the limitation of classroom teaching hours, classroom instruction for all courses is impossible. On the other hand, real opto-electric systems require comprehensive application of multi-disciplinary knowledge, which is not easily accomplished in classroom teaching. In order to make up the lack of the knowledge in opto-electric systems and help students learn how to apply multi-disciplinary knowledge into practice, NUDT, according to its own specialized characteristics, designs several synthetic experiments related to opto-electric systems including opto-electric imaging system, image processing and recognition system, telescope and night vision system, opto-electric tracking system, opto-electric guidance system and optical communication system. These experiments can dismantle the isolation between systems and knowledge modules and improve the ability to systematically and comprehensively apply separate knowledge modules shown in Fig. 1 into practice, which can furthermore broaden the knowledge range, shorten the distance between theory and engineering application and lay a solid foundation for the improvement of students' practice competence.

As the embodiment of the UKD theory, the opto-electric expertise teaching at NUDT is promoted step by step, from classroom teaching and practice teaching to system teaching, which follows not only the cognition law of students but also the principle of gradual improvement. Fig.2 shows the hierarchy difference between teaching and cognition. As shown in Fig.1 and Fig. 2, the opto-eletric teaching system at NUDT reflects the philosophy that Knowing is the main concern and Knowing and Doing are harmonized, which achieves the goal of knowing deeply, broadly and truly. 


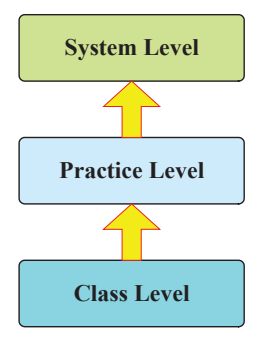

Fig.2 Progressive relationship between opto-electric expertise teaching and cognition behavior

\section{Hierarchies of opto-electric professional training model at NUDT}

According to the UKD theory, the core objective of learning is to be put into practice and to solve practical problems. The knowledge learned should be transferred into productive forces and used to create value. Furthermore, only practice can examine how well students master the knowledge learned. All the issues mentioned are the targets of the modern higher education development and reforming. The UKD theory provides higher education an effective method of bridging the gap between Learning and Practicing. As indicated by the UKD theory, Doing is the final target and also the only standard to examine Knowing. Therefore, based on the Knowing shown in Fig. 1 and Fig. 2, NUDT develops three action competence training levels as shown in Fig. 3. The cognition hierarchy is closely related with the knowledge learning and exercising, which is constituted by class level, practice level and system level. The connotations of these levels are shown in Fig. 1 and Fig. 2. As explained in section 2, cognition hierarchy takes Knowing and truth as the final target through the unification of Knowing and Doing.

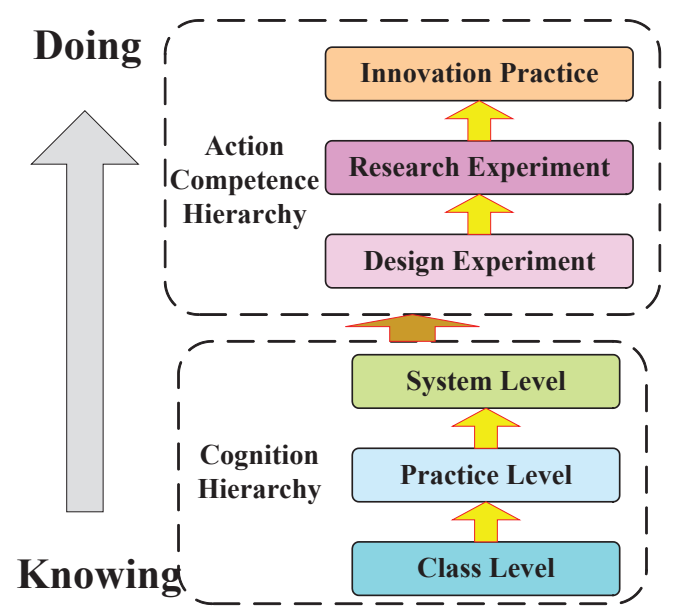

Fig.3 Structure of opto-electric professional competence training hierarchies

The action competence hierarchy targets capability cultivation and knowledge application and is comprised by design level experiments, research level experiments and innovation practice. The design level experiments mainly cultivate students to master how to use the knowledge learned to solve practical problems specified as certain applications in opto-electric fields. Students propose one goal and finish the design independently, which is similar as a project design (PD). For example, when designing a telescope, students can target long focus, large aperture, high resolution and high sensitivity, finish the system design by themselves and examine rationality, feasibility and 
optimization of the designed system. When designing an opto-electric measurement and control system, students can aim at certain application, select a proper optical measurement and determine the proper measurement method and equipments. If necessary, students can design and manufacture relevant signal processing circuits. If some control is required, students can select proper control variable and strategy, program and manufacture the demanding circuits. When the whole system is integrated and completed, a research report about the system's performance is available after some tests and examination. In design experiments, teachers' assignment is held as essential with students' self-selection as a supplement.

Research level experiments train students to comprehensively utilize the knowledge learned to discover, analyze and solve problems in practice, which usually are conducted in accordance with laboratory condition and current research projects. This level has a high requirement to students' competence. It is not available to all the students and only aims at the highly-qualified students. At NUDT, these qualified students can participate in some research projects such as novel laser technology, opto-electric precision sensing, low-dimension opto-electronic device, optical fiber technology, opto-biography and so on. Students can work together with teachers to design experiments, analyze experimental data, find problems and discuss how to solve them. At last, they can find some solutions to these problems. In the whole process, students will be well trained for future research. Innovation practice aims at cultivating students to comprehensively apply the knowledge learned to propose and accomplish worthwhile targets, which are usually proposed by students themselves, with the aid of teachers. These experiments, including the internet of things contest, opto-electric design contest and electronic design contest, are mainly conducted in laboratory. These contests can develop students' ability to distinguish worthwhile goal, research centered on this goal, analyze and solve problems, work in a team and manage a project, which is a good exercise for them to learn how to finish a small project and consequently improves their comprehensive action competence. These contests are of great benefits for the transformation from Knowing to Doing.

\section{Results and discussion}

In the recent five years, the undergraduate education of opto-electric major at NUDT insists on the UKD theory. Students will not only master the opto-electric professional knowledge, but also develops the Knowing competence in harmony with the Doing competence. The ability to transmute knowledge into action competence is greatly promoted. As shown by official statistics, all the students will be employed after graduation, $50 \%$ of whom will continue their postgraduate study. $15 \%$ will enter oversea universities to do their postgraduate study, and 7 students go to Oxford and Cambridge to pursue their $\mathrm{PhD}$ degrees. Until now, our students are awarded two outstanding prizes, 28 first prizes and 48 second prizes as shown in Table 1.

Table 1 Prizes awarded to students of opto-electric major at NUDT in recent five years

\begin{tabular}{|c|c|c|c|}
\hline Contest & $\begin{array}{l}\text { Outstanding } \\
\text { prize }\end{array}$ & $\begin{array}{c}1 \text { st } \\
\text { prize }\end{array}$ & $\begin{array}{l}\text { 2nd } \\
\text { prize }\end{array}$ \\
\hline International Undergraduate Micro-Nano Technology and Application Contest & & 1 & \\
\hline $\begin{array}{c}\text { National Undergraduate Internet of Things Innovation and Entrepreneurship } \\
\text { Contest }\end{array}$ & 2 & 2 & 4 \\
\hline National Undergraduate Opto-Electric Design Contest & & 3 & 6 \\
\hline $\begin{array}{c}\text { International Undergraduate "I CAN" Innovation and Entrepreneurship } \\
\text { Contest }\end{array}$ & & 2 & \\
\hline
\end{tabular}

Proc. of SPIE Vol. 10452 104520Z-5 


\begin{tabular}{|c|c|c|c|}
\hline International Mathematical Modelling Competition & & 19 & 30 \\
\hline National Mathematical Modelling Competition & & & 2 \\
\hline National Mathematics Contest & & & 2 \\
\hline National Physics Contest & & & 4 \\
\hline International Genetically Engineered Machine Competition & & 1 & \\
\hline Total & 2 & 28 & 48 \\
\hline
\end{tabular}

Opto-electric graduates at NUDT are commended by employers for solid basic knowledge, strong capability of analyzing and solving problems and good action competence. They usually become the backbone of their contingents immediately after employed.

As an ancient philosophy, the UKD theory is vigorous and has profound meaning, which is still very directive for modern higher education. Based on the UKD theory, NUDT makes a beneficial exploration of cultivating opto-electric expertise and competence. The result is inspiring. The main feature of the model is that it takes Doing as the thread and target of the true Knowing examination and enhances the unification of Knowing and Doing. It aims at providing a sounded solution to the Doing related problems. In cognition hierarchy, this model emphasizes a close coordination of classroom teaching, experiment teaching and systematic comprehensive experiments. True Knowing is the main goal of this model, while Doing can help experience and appraise Knowing, which can make students understand that Knowing is true only if examined by Doing. Otherwise, Knowing is superficial. In action competence hierarchy, the enthusiasm and creativity of students can be aroused through design experiments, research experiments and innovation experiments, which aim at fostering the Doing competence of students and transfers Knowing to something useful and significant to our society. Furthermore, students will be aware of the value and true essence of Knowing. However, the UKD training model requires high-qualified teachers. A high-qualified teaching team is the base of this model, which should be well-trained and full of research experience with solid basic knowledge and extraordinary action competence.

\section{Bibliographies:}

[1] Song Xin, Yin Liu, Jing Chen, et al. The application of the 'Unity of Knowing and Doing' philosophic thought in educating outstanding engineers [J], Journal of China electric power education, 2012(20): 15-16, 2012.

[2] Lizhi Kong, Suolan Liu. A research on the university teaching based on the 'Unity of Knowing and Doing' theory [J], Journal of China electric power education, 2013(25): 68-69, 2013.

[3] Guoqin Li, Shuang Sun, Hui Yang. Mechanical teaching research and practice based on the 'Unity of Knowing and Doing' theory [J], Journal of university education, 2015(2):141-143, 2015. 